\title{
Times Square, Times Out! A Speculative Approach on Public Space Practice
}

\author{
ANA MORCILLO PALLARES
}

University of Michigan

\begin{abstract}
480,000 tourists and locals walk through Times Square daily. ${ }^{1}$ A global destination oversaturated by millions of visitors around the world, a space of discrepancy between locals and administrators, shared by spectators and sanitation workers, entertainment and consumerism, filled by families, tourists, security cameras and performers; Times Square represents a case of study where public space is tested, produced and denied in everyday and extraordinary ways. The Square's dense and diverse pedestrian activity offers a unique design challenge to explore more than ever public space practices addressing the pros and cons of the changing politics and city protocols, citizen's demands and the principles of what makes spaces public, what it stands for, and how to provide an environment for interaction.
\end{abstract}

\section{INTRODUCTION}

Today public spaces in the urban centers of New York City, Barcelona, Paris, London and beyond, face the new millennium as "secure" family-friendly crossroads of consumerism, tourism and entertainment in the era of urban surveillance, mass capitalism and radical political positions. In light of these recent controversies, the following article highlights three speculative projects from an undergraduate design studio at Taubman College of Architecture and Urban Planning, at the University of Michigan. The studio invited students to launch design solutions for weary Times Square users caught in the cinematic and media epicenter of New York City. Within this context, the projects explore the speculative role of the designers in today's public space practice, in order to react and critic the face of new global threats that require the rethinking of how we use, design and implement public areas in the contemporary city.

This debate in relation with the practice of public space points to a basic problem: we are never quite sure what it is or what it is for. We have this naive sense that public space is something open, free and happy. However, the reality is very different. The "other" or the diversity is what is missing from the kind of public space in most of our squares, plazas, and pocket parks. And this is what makes it, at the same time, valuable and vulnerable. In this scenario, Times Square, as a global public place and as "a unique physical 'experience of place,' which derived from its small-scale buildings, open space, and illuminated lights, ${ }^{2}$ holds a promise of a liberating space through its daily battle waged over it by its inhabitants.

\section{'THE BIG EYEBALL'}

\section{A SPECULATIVE APPROACH ON SURVEILLANCE}

In a 'post-9/11 world,' it is hard to imagine New York City without the omnipresent gaze of surveillance cameras and life time monitoring. As Setha M. Low pointed out: "what was once considered 'Big Brother' technology and an infringement of civil rights is now a necessary safety tool with little, if any, an examination of the consequences. ${ }^{3}$ New Yorkers' neurotic impulse of overprotection led the fever of urban surveillance to quickly multiply. According to the latest public data: "only the New York Police Department has about 2,000 cameras scanning the streets, sidewalks, rooftops, parks, bridges and tunnels of New York day and night. There's 7,000 more in public housing and another 4,000 in the subway." ${ }^{4}$ But of all these spaces, as The New York Times reported that, "in Times Square perhaps, more than any other place in the city, our movements are being recorded a hundred different ways." ${ }^{5}$

Surprisingly, it seems that no one cares about it. On one side of the camera, the overwhelming collection of data is being reviewed by people who have been staring at the screen for so long that they have lost focus. On the other side, the tiny size of these electronic eyes go unnoticed by the public who vote for more of them in order to increase security in the public realm. The consequences: safety over privacy, protection over civil rights. In order to push back this expanding network, organizations such as, the New York Civil Liberties Union, questions what happens to the footage after its recording. Is it deleted or is it stored? Is it used for other means beyond the security in the streets? Is it likely to address this invasive role of surveillance from an architectural point of view? What could happen if it were possible to make visible all those videos in one central place, like they do in the Bourne movies?

In response to this criticism facing the era of urban surveillance, the proposal titled 'the Big Eyeball' imagines an alternative scheme for Times Square. The project exposes a dramatic scalar relationship of the surveillance network that records the everyday occurrences at the intersection of the world. The author, Chihiro Fukai, proposed an over dimensioned dome-type security camera at the crossroads of Broadway and 42nd street, in the heart of Times Square (figure 1). As Robert Venturi and Denise Scott Brown did with their proposal for 'the Big Apple' in 1984, here 'the Big Eyeball' introduces again a focal point in the intersection, at the time that plays with absurdity and serendipity. Or as the urban critic, Paul Goldenberg, put into words: "the genius of ['The Big Apple'] 

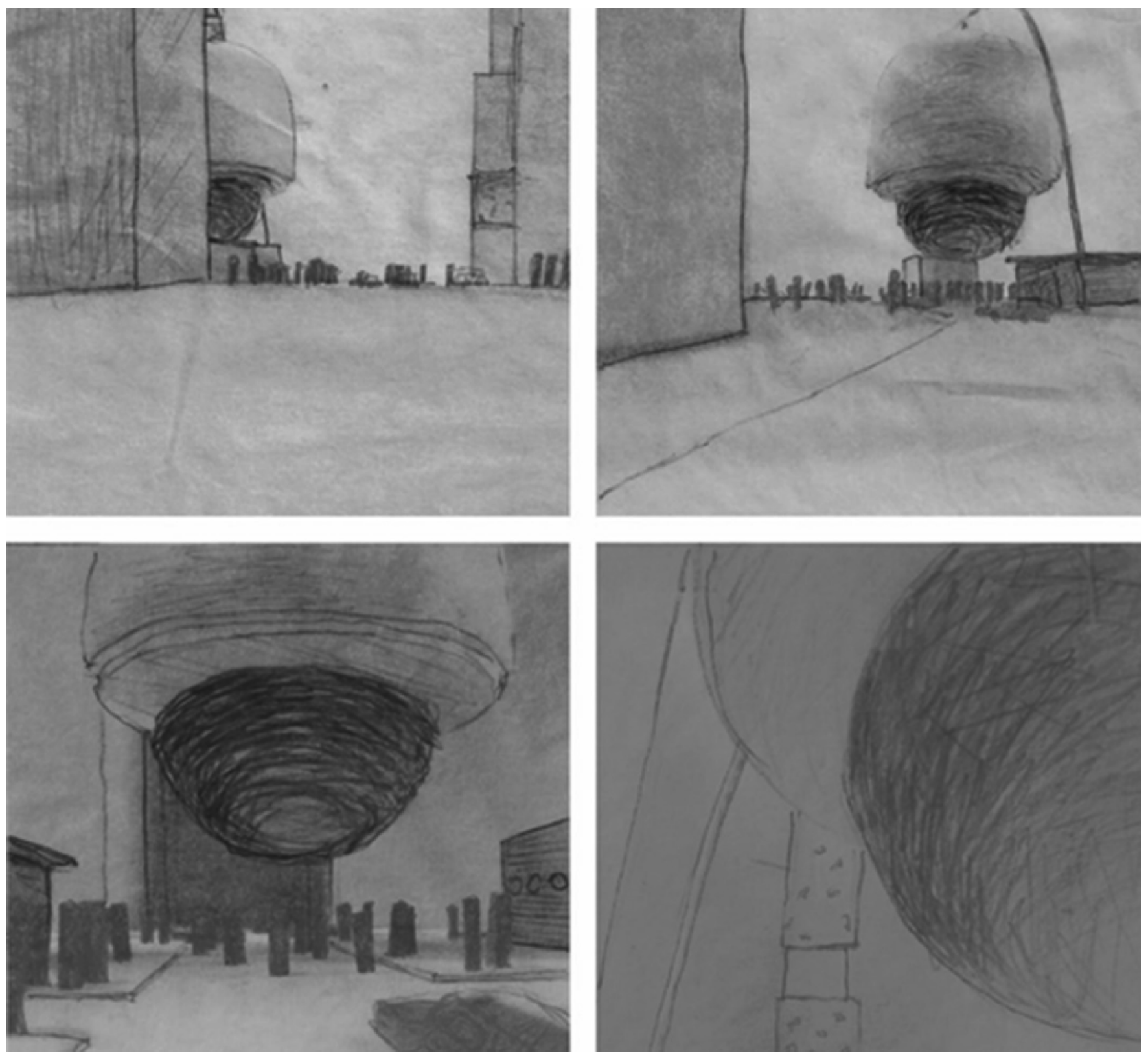

Figure 1: 'The Big Eyeball' by Chihiro Fukai. Proposal of the sequencial approach from the plaza level.

lies in its ability to manipulate proportion and the element of surprise in such a way as to make us think of the apple as a monumental object, not as a common piece of fruit."

The pairing of contrast of shapes and scaler ambiguity is managed by two spatial strategies. On one hand, the camera's smooth volume is opposite to the sharpness and angularity of surroundings buildings and billboards. On the other hand, its colossal dimensions, 25 meters in diameter, together with its exaggerated lower position, create a suffocating and compressed space in between the suspended dome and the pedestrian level. In addition to this, the Eyeball's strategic location is designed to be seen from multiple street intersections accentuating the impact and tension in the urban scene. More specifically, the Eyeball's subtle physical connection to the New York Police Department kiosk and the US Army recruitment pavilion reminds us all that we are constantly being targeted by something or someone behind the scenes and beyond our knowledge. In the end, a certain fact about 'the Big Eyeball' is its contradiction to the former Mayor Michael Bloomberg's statement when he argued that privacy was off the table after 9/11 when he said: "One of the things for sure is that you're never going to know where all of our cameras are." 7 

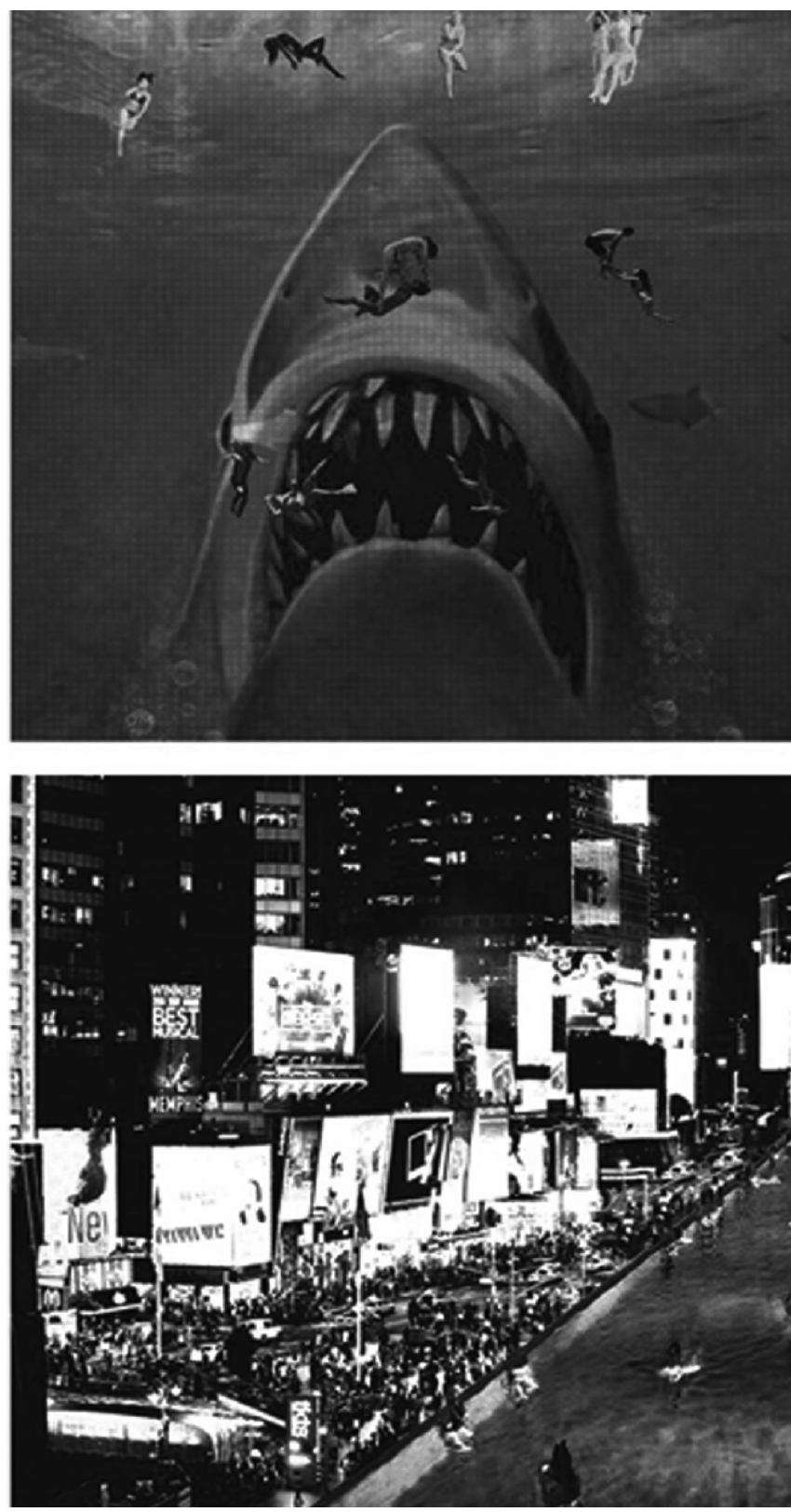

Figure 2: 'One Mile-Board Pool' by Amanda Ai. Above> Scale ambiguity of the vertical illuminated billboard superposed with the users silhouettes. Bellow> Top view of the infinite pool looking towards Times Square.

\section{'ONE MILE-BOARD POOL'}

\section{A SPECULATIVE APPROACH ON CONSUMERISM}

Today, in a Times Square colonized by the "hyper consumption and sidewalks filled with shoppers which can enjoy with scant cultural or intellectual dissent," ${ }^{8}$ the free-market capitalism has destroyed past local business. In this sense, one of the most radical transformations experienced by the area took place under Mayor Rudy Giuliani administration during the 90s when the intersection went from being the capital of the decline and porn industry to the capital of consumerism. The policy tool which was key for allowing this process was the reclamation of Times Square properties through the eminent domain. This decision was unilaterally taken by the City arguing that "Times Square was physically, economically, and socially blighted and that its redevelopment would better the area and the city in general." ${ }^{9}$ The following step was the well-known colonization of Times Square by mass corporations such as the Walt Disney Company which many scholars analyzed as part of what considered to be the "Disneyfication" or end of public space. ${ }^{10}$

However, this chapter in the controversy of Times Square history is taken as an opportunity. A challenge to address practices not necessarily realistic or practical, but provocations in order to open a debate about how much is left to be done in today's hyper dense main commercial junctions. In this search for the perfect marriage between consumerism, mass tourist destination, culture, pleasure and available space, the author, Meichen Ai, envisioned 'One Mile-Board Pool' (figure 2). The proposal is understood as a hypothetical bathhouse for Times Square placed in the vacant interstitial gap in between the illuminated billboards and the buildings that support them. What a priori seems an impossible task due to the physical restrictions of the site together with the billboards infrastructure complexity, it is not.

One Mile-Board Pool achieves a fun design solution, where the idea of a mile-long pool snaking behind the ads scenes of the illuminated billboards plays a double sophisticated role. On one hand, the extreme narrowness of the water feature introduces the user to an individual, anonymous and an intimate space at the time that it invites one to self-reflect and relax in the middle of the city's craziest maelstrom. On the other hand, a kaleidoscopic vertical stage of moving images, videos and lettering allows to maximize the ambiguity of scale in between the users' silhouettes and the ads from the street level. A rich and imaginative scenario that provides all the ingredients to reconcile, once again, culture, intelligence and commercialism from a place that experienced "the removal of all disorderly cultural elements that once disturbed the members of the prosperous white middle class." ${ }^{11}$

\section{'DEPLOYING ABSURDITY'}

\section{A SPECULATIVE APPROACH ON ENTERTAINMENT}

Most recently, in 2009, the pedestrianization of Times Square was part of the NYC Plaza program which created more than fifty new plazas, in all five boroughs under the administration of Mayor Michael R. Bloomberg. However, six years later, the promise of a pedestrian space for everyone didn't work. Mayor Bill di Blasio was considering removing the plazas from the area in order to address the proliferation of street performers, most notably topless women wearing body paint who panhandle masses of tourists for tips. These "obscene" scenes brought up vivid memories of the decay of the square over the last decades of the twentieth century. During the 70 s and 80 s prostitution by all genders, crime, drug trade, 

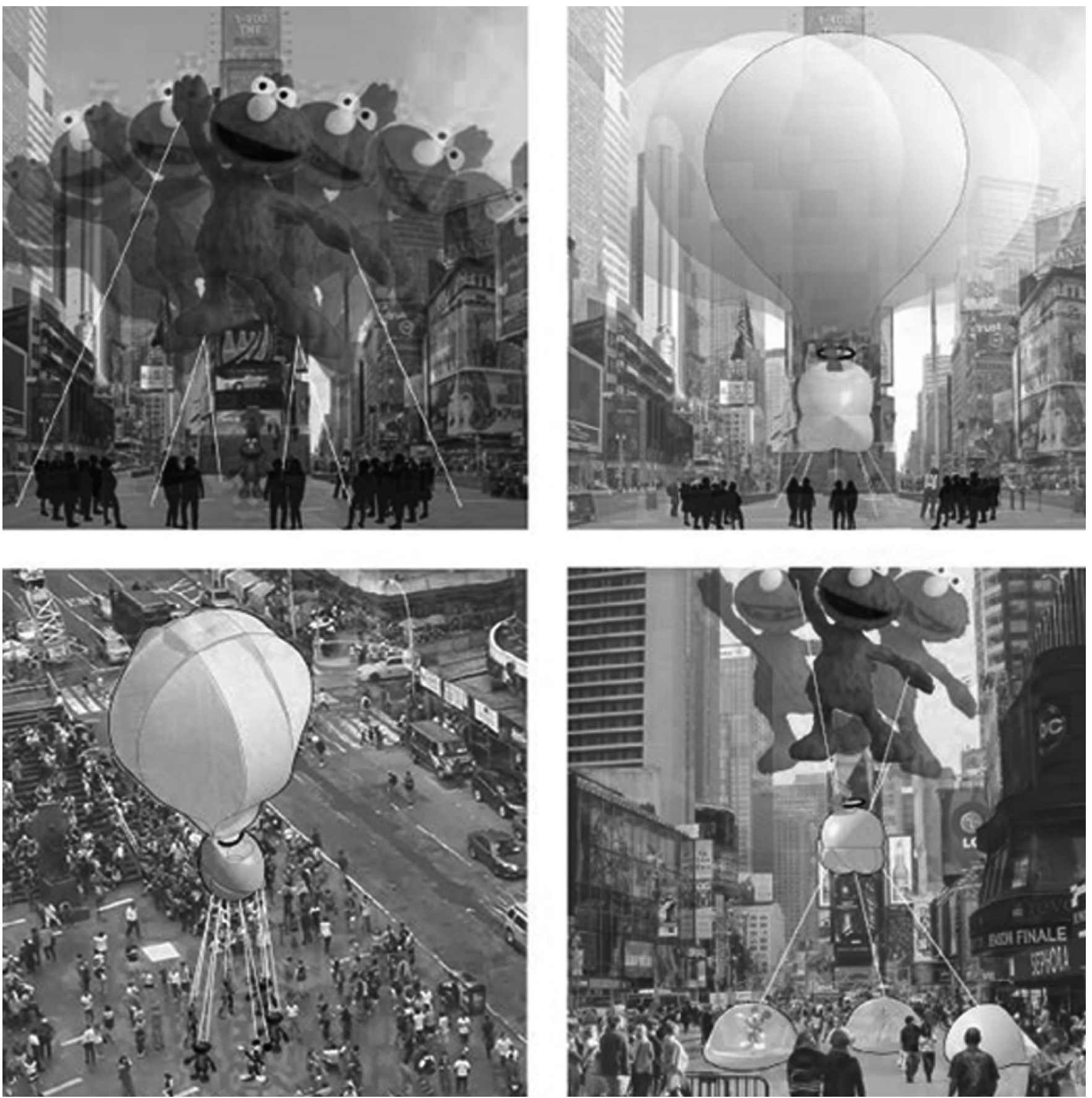

Figure 3: Alex Waga's vision to create a mobile and modular artefact to provide streets panhandlers a stage in Times Square.

alcoholism and smuggling were part of everyday life and seemed to finish with the golden years of Times Square as the entertainment district of the world. Di Blasio argued that: "we're going to look at what those pros and cons would be. You could argue that those plazas have had some very positive impacts. You could also argue they come with a lot of problems."12

In light of this question of history, memory and controversy, the media epicenter of New York City faces another added pressure: terrorism. In 2017, attacks by individuals who improvised low-tech explosive devices led the City implement unprecedented security precautions, beyond the traditional physical barriers, by increasing security in the nearby area and a closer surveillance in the square. This recent terrorism threat together with the negative interactions between street performers and visitors led to the deployment of new spatial devices by the Department of Transportation. These new additions would allow to subdivide the plaza with different physical mechanisms in order to increase security and organize the 
space in three different areas: "the 'Chill Zone,' where people can 'sit, nosh, mediate.' 'The Express Lanes,' which allow for unencumbered pedestrian access through the plaza, and 'Designated Activity Zones' where commercial activity is permitted, along with taking photos, and giving tips." ${ }^{13}$

The introduction of these new rules, by demarcating different users' areas with painted boxes on the floor, by limiting the traffic access with permanent benches, fixed bollards and planters and by increasing the surveillance with a rising number of cameras, is something exceptional. Although the City has traditionally had strong plaza rules for vending and performance designation in parks and plazas, there is no precedent in the history of the urban policy of the City for these great amount and permanent and strict restrictions, in such a limited and crowed space, like Times Square. The plaza has become one of the only open spaces of the city where your activity dictates if you can stay in a specific spot or not. This spatial limitation has not been the extent of the polemic. It raises many questions in regards of the lack of freedom of movements of a certain group of users, as the street performers, in an open and public space in the city. As a Spider-Man costume character expresses: "I have a right to walk in public space in my costume. If somebody wants to take pictures with me, that's their right."14

Following this recent controversy, the proposal 'Deploying Absurdity' (figure 3) by Alex Waga imagines to approach this conflict by introducing different spatial environments to elicit a new interaction between visitors and performers. In this sense, the strength of the project is based on addressing di Blasio's position, recognizing that the former and uncontrolled situation created by the great number of performers on the plaza was unsustainable. However, if di Blasio's option is based on a reduction of the space where the interaction among visitors and users can occur, Waga's vision is to create an inflatable platform able to multiply, host different programs and anticipate ephemeral scenarios for the costume characters who are using the place. This new mobile and modular artifact provides the ability of adaptation to the urban context, allowing the curation of different activities among users in multiple directions. This panhandler stage-shelter allows for private areas for the users to rest, and at the same time uses digital media to invite the public to participate with performers. The inflatable device serves as a non-stationary screen which is able to provide an interactive, temporal and ever-changing landscape within the square.

\section{CONCLUSIONS}

The singularity of these speculative ideas for an open and public space as Times Square, manifest the complex and effervescent future of the design practice in today's city epicenters. These proposals delve into different approaches and reactions to conflicts shared by many capitals' interests in the world: surveillance, consumerism and entertainment.
In this sense, the different mechanisms which are proposed by undergraduate students incorporate notable spatial opportunities for collective use that intend to promote social interactions in a place where there are genuine and evident economic interests. A place where there is a need to facilitate public engagement to optimize consumerism but which is crucial to propose different alternatives far from the dull language of the mass-media capitalism. These proposals allow for a diversification of uses and a flexibility of programs that are key at the moment of promoting and establishing a foundation for the authentic social interaction in the city.

From the analysis of these three different projects, there are two main conclusions. On one hand, the contextualization of the conflict is key to comprehend the influence of social, economic and political dimension in the architectural project. On the other hand, this paper pretends to shed light on the vulnerability of the open public space in the city, which in the case of New York, its status depends on the Mayor's agenda, and a not always transparent process in the generation and strengthening of the public space and the calibration of the fragile balance in between public and private interests.

\section{ENDNOTES}

1. Jan Gehl, Jeff Risom, and Julia Daily, "The Naked Truth," The New York Times, (August 31, 2015)

2. Lynne B. Sagalyn, Times Square Roulette: Remaking the City Icon. (Cambridge Massachusetts: MIT Press, 2003).

3. Setha M. Low, The Erosion of the Public Space. Paranoia, surveillance and privatization in New York City. (London : Routledge, 2005).

4. Will Doig. "New Yorkers Called For More Cameras," NEXT CITY, (June 14, 2017).

5. Ariel Kaminermay, "Has the Big Apple Become the Big Eyeball?" The New York Times, (May 7, 2010)

6. "Venturi and Johnson: the Big Apple," http://skyscraper.org/EXHIBITIONS/ TIMES SQUARE/venturi.php

7. Jill Colvin, "Bloomberg Uses Terror Announcement to Bash Anti-Camera 'Special Interests," Observer, (April 25, 2013).

8. Penelope Green, "MIRROR, MIRROR; Consumerism and its Discontents," The New York Times, (December 17, 2000)

9. Themis Chronopoulos, Spatial Regulation in New York City: From Urban Renewal to Zero Tolerance. (London : Taylor \& Francis, 2011).

10. Michael Sorkin, Variations on a Theme Park: The New American City and the End of Public Space. (New York : Hill and Wang, 1992).

11. Quote by Brendam Gill. Source: Themis Chronopoulos, Spatial Regulation in New York City: From Urban Renewal to Zero Tolerance. (London : Taylor \& Francis, 2011).

12. Michael M. Grynbaum and Matt Flegenheimer, "Mayor de Blasio Raises Prospect of Removing Times Square Pedestrian Plazas," The New York Times, (August 20, 2015).

13. Tanay Warerkar "Times Square's Designated 'Activity Zones' Are Becoming a Reality," Curbed New York, (June 9, 2016).

14. Emma Fitzsimmons, "New York Moves on Restricting Costumes Characters in Times square," The New York Times, (April 7, 2016). 